\title{
PENGARUH KESELAMATAN KERJA DAN LINGKUNGAN KERJA TERHADAP SEMANGAT KERJA DI CV. MEGA JAYA SURABAYA
}

\author{
Ilham Rizki Santosa ${ }^{1}$, I Ketut Surabagiarta ${ }^{2}$ \\ Universitas PGRI Adi Buana Surabaya1,2 \\ Email : ilhamrizki858@gmail.com
}

\begin{abstract}
ABSTRAK
Bertujuan ingin mengetahui serta menganalisis adanya pengaruh dari parsial, simultan atas variabel keselamatan kerja dan variabel lingkungan kerja terhadap variabel semangat kerja. Metode yang di pakai kuantitatif, lalu pengambilan sampel menggunakan sampel jenuh. Sedangkan pengambilan datanya melalui kuisioner. Analisis data diperoleh dari 100 responden yang diteliti kemudian diolah menggunakan SPSS 25 dengan analisis linier berganda. Dengan begitu menghasilkan kesimpulan pada masing-masing variabel yaitu keselamatan kerja, lingkungan kerja yang terdapat pengaruhnya secara parsial terhadap semangat kerja, hasil sig diperoleh $0,000<0,05$, dan lingkungan kerja mempunyai pengaruhnya simultan terhadap semangat kerja. tingkat signifikan $0,000<0,05$. Variabel bebas pada penelitian ini berpengaruh sebesar $83,2 \%$ terhadap variabel terikat.
\end{abstract}

Kata Kunci : keselamatan kerja, lingkungan kerja, semangat kerja.

\begin{abstract}
This research aims to determine and analyze the presence of partial and simultaneous influence of occupational safety and environmental variables on the work spirit. The method on this study uses a quantitative approach, while the sampling technique on this research is a saturated sample. This research uses the data retrieval techniques in the form of a questionnaire. The analysis of data obtained from 100 respondents studied was subsequently processed into multiple linear regression analyses using SPSS version 25. This study resulted in the conclusion that in each occupational safety and work environment variables were partially affected by the working spirit, a significant result was obtained at $0,000<0.05$, and both of these free variables were simultaneously influential for the variable bound to a significant level $0,000<0.05$. The free variables in this study affected $83.2 \%$ of the bound variables.
\end{abstract}

Keywords: occupational safety, working environment, working spirit.

\section{PENDAHULUAN}


Dalam sebuah perusahaan pekerja ialah aset utama, karena berhasil tidaknya bergantung pada kemampuan yang dimiliki pekerja. maka dari itu perlu diperhatikan secara khusus dan dikelola dengan sebaik mungkin. Dalam perusahaan semangat kerja diperlukan agar para pekerja mempunyai semangat yang tinggi dalam bekerja, dengan begitu akan berdampak pada hasil kerja yang mereka lakukan. Untuk meningkatkan semangat kerja perusahaan harus memiliki keselamatan kerja. Dalam suatu perusahaan keselamatan kerja wajib dimiliki, karena keselamatan kerja hal yang paling penting untuk meminimalisir kecelakaan dalam bekerja. Dengan adanya keselamatan kerja diharapkan para karyawan merasa nyaman dan amanketika melakukan pekerjaan. Dengan timbulnya rasa aman dan nyaman pada diri para karyawan maka akan berpengaruh meningkatnya rasa semangat yang miliki.

Kenyataannya pada aspek keselamatan kerja itu hanya membutuhkan pengawasan. Nah pengawasan yang paling murah dan paling efisien itu kenyataan kepada diri setiap karyawan masing-masing. Maka tugas keselamatan kerja itu semestinya bukan hanya tugasnya orang K3 semata, membedakan seluruh karyawan

Selain keselamatan kerja, lingkungan kerja juga harus di perhatikan sebab lingkungan nyaman maka berakibat kepada semangat kerja nya karyawan. Sebab kantor ialah rumah kedua bagi para karyawan sehingga banyak yang menghabiskan waktunya di kantor karena sebuah tuntutan pekerjaan. Oleh sebab itu setiap perusahaan sebaiknya membuat lingkungan kerja yang lebih kondusif dan sehat. Dengan begitu pekerja akan nyaman sehingga akan timbul rasa bersemangat kerja yang tinggi pada para bekerja.

Di perusahaan atau organisasi semangat kerja pegawai adalah hal yang sangat penting. Apabila jika semangat kerja karyawan kurang, maka akan berkibat pada hal-hal yang tidak diharapkan pada organisasi atau perusaaan, seperti kerja yang tidak maksimal. Namun apabila para karyawan memiliki semangat kerja yang sangat tinggi, bisa berdampak pada hasil kerja yang baik sehingga tujuan dapat tercapai.

Namun tak jarang semangat kerja pun melemah dengan berbagai sebab dan pasti setiap orang memiliki alasan yang beda-beda. Ketika semangat kerja menurun dapat atasi dengan cara membuat suasana kantor terasa nyaman, Pekerjaan jangan dianggap berat dan dijadikan beban, Rancang pekerjaan dan dahulukan yang prioritas, Berteman dengan orang-orang yang ceria dan penuh semangat, Tanamkan dalam diri, bahwa antara kamu dan perusahaan saling membutuhkan, Manfaatkan weekend sebaik mungkin untuk me-time agar pikiran kamu fresh lagi, Selalu melihat ke bawah dan jangan lupa bersyukur.

Berdasarkan permasalahan diatas, tertarik dalam memilih judul: "Pengaruh Keselamatan Kerja dan Lingkungan Kerja Terhadap Semangat Kerja Karyawan CV. Mega Jaya Surabaya".

Seperti yang sudah dipaparkan di latar belakang bisa ditentukan rumusan masalah yaitu: Apakah terdapat pengaruh dari Keselematan Kerja terhadap Semangat Kerja Karyawan CV. Mega Jaya Surabaya? Apakah benar Lingkungan Kerja mempunyai pengaruh terhadap Semangat Kerja Karyawan CV. Mega Jaya Surabaya? Apakah Keselamatan Kerja dan Lingkungan Kerja berpengaruh simultan pada Semangat Kerja Karyawan CV. Mega Jaya Surabaya? 
Tujuan yang sejalan dengan rumusan masalah yaitu untuk megetahui dan menganalisis apakan terdapat pengaruh variabel bebas pada variabel terikat baik pengujian dalam parsial ataupun pengujian dalam simultan.

\section{TINJAUAN PUSTAKA DAN HIPOTESIS}

\section{Landasan Teori}

Menurut M.Manullang (2006:3) mengatakan dalam mencapai tujuan Manajemen Sumber Daya Manusia seni dengan memakai manusia lain yang tetap memperhatikan hak dan kewajiban, selain itu mempunyai tujuan sama dan sistem pengorganisasian jelas.

Sedarmayanti (2018:373) mengartikan bahwa Keselamatan Kerja ialah perlindungan untuk seseorang atau karyawan yang menunjukkan kondisi aman, selamat, kerusakan maupun kerugian.

Nitisemito (2018:183) berpendapat Lingkungan kerja ialah dimana seseorang yang tengah melakukan pekerjaan mampu mempengaruhi diri dalam menjalankan tugasnya dari keseruluhan dengan alat perkakas serta berbagai bahan yang dihadapi lingkungan di sekitarnya.

Menurut Hasibuan (2009:94) yang dimaksud Semangat kerja melakukan semua pekerjaan secara giat juga mampu berdisiplin guna mencapai prestasi kerja maksimal.

\section{Hipotesis}

Adapun hipotesis dari penelitian ialah :

Keselamatan Kerja memiliki pengaruh semangat kerja karyawan pada CV. Mega Jaya Surabaya

Dimana variabel Lingkungan Kerja adanya pengaruh pada semangat kerja karyawan di CV. Mega Jaya Surabaya

Keselamatan Kerja dan Lingkungan Kerja secara simultan yang berpengaruh terhadap semangat kerja yang dimiliki oleh karyawan di CV. Mega Jaya Surabaya.

\section{METODE}

Metodemenggunakan kuantitatif. Sampel yang dimiliki sebesar 100 responden CV. Mega Jaya Surabaya dan teknik pengambilan sampel memakai teknik sample jenuh. Teknik pengumpulan data dengan memakai kuesioner.

\section{HASIL}

\section{Hasil uji Validitas}

Tabel ini ialah hasil uji validitas yang masing-masing variabel penelitian:

Tabel 1

Hasil Pengujian dari Variabel Keselamatan Kerja

\begin{tabular}{llcll}
\hline Pernyataan & $\begin{array}{c}\mathbf{R} \\
\text { hitung }\end{array}$ & $\begin{array}{c}\mathbf{R} \\
\text { tabel }\end{array}$ & $\begin{array}{l}\text { Taraf } \\
\text { Signifikan }\end{array}$ & Keterangan \\
\hline 1 & 0,432 & 0,195 & 0,05 & Valid \\
2 & 0,648 & 0,195 & 0,05 & Valid \\
3 & 0,386 & 0,195 & 0,05 & Valid
\end{tabular}


Vol. 1 No. 1 Desember 2020

$\begin{array}{lllll}4 & 0,784 & 0,195 & 0,05 & \text { Valid } \\ 5 & 0,691 & 0,195 & 0,05 & \text { Valid } \\ 6 & 0,784 & 0,195 & 0,05 & \text { Valid } \\ 7 & 0,691 & 0,195 & 0,05 & \text { Valid } \\ 8 & 0,728 & 0,195 & 0,05 & \text { Valid } \\ 9 & 0,479 & 0,195 & 0,05 & \text { Valid } \\ 10 & 0,545 & 0,195 & 0,05 & \text { Valid }\end{array}$

Tabel 2

Hasil Uji Variabel dari Lingkungan Kerja

\begin{tabular}{lllll}
\hline Pernyataan & $\begin{array}{c}\mathbf{R} \\
\text { hitung }\end{array}$ & $\begin{array}{c}\mathbf{R} \\
\text { tabel }\end{array}$ & $\begin{array}{l}\text { Taraf } \\
\text { Signifikan }\end{array}$ & Keterangan \\
\hline 1 & 0,659 & 0,195 & 0,05 & Valid \\
2 & 0,407 & 0,195 & 0,05 & Valid \\
3 & 0,692 & 0,195 & 0,05 & Valid \\
4 & 0,532 & 0,195 & 0,05 & Valid \\
5 & 0,638 & 0,195 & 0,05 & Valid \\
6 & 0,518 & 0,195 & 0,05 & Valid \\
7 & 0,528 & 0,195 & 0,05 & Valid \\
8 & 0,456 & 0,195 & 0,05 & Valid \\
9 & 0,314 & 0,195 & 0,05 & Valid \\
10 & 0,260 & 0,195 & 0,05 & Valid \\
11 & 0,335 & 0,195 & 0,05 & Valid \\
12 & 0,481 & 0,195 & 0,05 & Valid \\
13 & 0,693 & 0,195 & 0,05 & Valid \\
14 & 0,511 & 0,195 & 0,05 & Valid
\end{tabular}

Tabel 3

Nilai Pengujian Variabel Semangat Kerja

\begin{tabular}{llcll}
\cline { 1 - 2 } Pernyataan & $\begin{array}{c}\mathbf{R} \\
\text { hitung }\end{array}$ & $\begin{array}{c}\mathbf{R} \\
\text { tabel }\end{array}$ & $\begin{array}{l}\text { Taraf } \\
\text { Signifikan }\end{array}$ & \\
\hline 1 & 0,640 & 0,195 & 0,05 & Kalid \\
2 & 0,461 & 0,195 & 0,05 & Valid \\
3 & 0,564 & 0,195 & 0,05 & Valid \\
4 & 0,753 & 0,195 & 0,05 & Valid \\
5 & 0,557 & 0,195 & 0,05 & Valid \\
6 & 0,393 & 0,195 & 0,05 & Valid \\
7 & 0,468 & 0,195 & 0,05 & Valid \\
8 & 0,753 & 0,195 & 0,05 & Valid
\end{tabular}

Tabel di atas menunjukan hasil jika rhitung > rtable. jadi memperoleh dikatakan jika semua item yang ada di pertanyaan dinyatakan valid. 


\section{Hasil Uji reliabilitas}

Dari uji reliabilitas dapat diketahui hasilnya, yaitu:

Tabel 4

Hasil Uji dari Reliabilitas

\begin{tabular}{lll}
\hline Variabel & $\begin{array}{l}\text { Cronbach } \\
\text { Alpha }\end{array}$ & Keterangan \\
\hline $\begin{array}{l}\text { Keselamatan } \\
\text { Kerja }(X 1)\end{array}$ & 0,815 & Reliabel \\
$\begin{array}{l}\text { Lingkungan } \\
\text { Kerja }(X 2)\end{array}$ & 0,767 & Reliabel \\
$\begin{array}{l}\text { Semangat } \\
\text { Kerja }(Y)\end{array}$ & 0,702 & Reliabel \\
\hline
\end{tabular}

Hasil dari pengujian realibilitas menunjukkan jika semua kuesioner reliabel karena nilai cronbach aplha $>0,6$.

\section{Pengujian Asumsi Klasik}

a. Hasil dari Uji Heterokedastisitas

Dari perhitungan telah dilakukan, yang diperoleh hasil sebagai berikut ini:

Tabel 5

Penguji Heteroskedastisitas

\begin{tabular}{lll}
\hline Variabel & T & Sig \\
\hline Keselamatan Kerja (X1) & -.265 & .791 \\
Lingkungan Kerja (X2) & .822 & .413 \\
\hline
\end{tabular}

Dari hasil diatas nilai signifikansi memiliki nilai signifi lebih 0,05 sehingga tidak terjadi adanya heteroskedastisitas pada regresi model ini.

\section{b. Hasil Uji dari Normalitas}

Guna Mengetahui apakah dalam regresi ini, dari variabel bebas dan variabel terikat, berdistribusi normal atau tidak.

Tabel 6

Uji Normalitas

\begin{tabular}{cc}
\hline & $\begin{array}{c}\text { Unstandardized } \\
\text { Residual }\end{array}$ \\
\hline $\mathrm{N}$ & 100 \\
Test Statistic & .061 \\
Asymp. Sig. & \\
(2-tailed) & $.200^{c}$ \\
\hline
\end{tabular}

Hasil pengujian diatas, diperoleh nilai Asymp.Sig 0,200 yang artinya data yang digunakan berdistribusi normal.

\section{c. Pengujian Autokorelasi}


ialah hasil yang diperoleh uji autokorelasi, yaitu:

Tabel 7

Uji Autokorelasi

\begin{tabular}{c}
\hline Durbin Watson \\
\hline 1.923 \\
\hline
\end{tabular}

Berdasarkan pengujian autokorelasi dapat dikatakan nilai durbin watson 1.923 dimana hasil lebih besar dari DU 1.715 yang artinya tidak terjadi autokorelasi.

\section{Hasil dari Pengujian Analisis Regresi Linear Berganda}

Diketahui hasil regresi linier berganda, yakni:

$$
\text { Uji } 8
$$

\begin{tabular}{|c|c|c|}
\hline \multirow[t]{2}{*}{ Variabel } & \multicolumn{2}{|c|}{$\begin{array}{l}\text { Unstandarized } \\
\text { Coefficients }\end{array}$} \\
\hline & B & Std. Error \\
\hline (Constant) & -2.847 & 1,766 \\
\hline Keselamatan & & \\
\hline Kerja (X1) & -.647 & .075 \\
\hline Lingkungan & & \\
\hline Kerja (X2) & 1.074 & .067 \\
\hline
\end{tabular}

Secara sistematis dapat ditulis hasil persamaannya sebagai berikut :

$Y=-2,847+-, 647 X 1+1,074 X 2+e$

Berdasarkan persamaan tersebut, dapat dijelaskan sebagai berikut :

a. Nilai konstanta (a) $-2,847$

Konstanta senilai -2,847 menyatakan jika variabel bebas yaitu Keselamatan Kerja (X1) Lingkungan Kerja (X2) anggap konstan, jadi semangat kerja mendapatkan penilaian -2,847. Artinya bahwa rata-rata variabel lain yang diluar model berdampak negatif pada semangat kerja.

b. Koefesien variabel keselamatan kerja (X1) sebesar -,647. Koefisien regresi (b1) sebesar ,647 memberikan arti bahwa keselamatan kerja dalam penilaian karyawan ada peningkatan sebesar satu satuan maka keselamatan kerja dapat meningkat -,647 dengan anggapan variabel keselamatan kerja dianggap konstan (nol).

Nilai koefesien variabel lingkungan kerja (X2) sebesar 1,074. Koefisien regresi (b2) sebesar 1,074 memberikan arti bahwa lingkungan kerja dalam penilaian karyawan ada peningkatannya sebesar satu maka semangat kerja dapat meningkat 1,074 dengan anggapan variabel lingkungan kerja dianggap konstan (nol).

\section{Hasil Uji Hipotesis}

1. Uji F (Pengujian hipotesis yang dilakukan cara simultan)

Menguji bersamaan pengaruh variabel bebas memakai uji F. Hasil perhitungan regresi secara simultan memperoleh sebagai berikut :

\begin{tabular}{lll}
\multicolumn{3}{c}{ Tabel 9 } \\
Uji F & \\
\hline & F & Sig \\
\hline Regression & 239.748 & $.000^{\mathrm{b}}$ \\
\hline
\end{tabular}


Hasil diatas didapatkan nilai sig. 0,000 lebih kecil dari $\alpha=0,05$. Sedangkan hasil uji $F$ memperoleh sebesar 239.748 > Ftabel 3,09 ( $\mathrm{df}=98$ ). Jadi hasil pengujian menunjukkan diterimanya hipotesis 3 menyatakan keselamatan kerja dan lingkungan kerja mempunyai pengaruh secara simultan terhadap pada semangat kerja CV. Mega Jaya Surabaya diterima.

\section{Uji t (Uji Hipotesis dengan cara Parsial)}

Untuk diuji kebenarannya yang memakai uji dari parsial. Penguji mengetahui taraf sign ( $p-$ value), taraf signifikan dihasilkan melalui perhitungan di bawah 0,05 hipotesis dikatakan diterima, dan sebaliknya.

\begin{tabular}{lll}
\multicolumn{3}{c}{ Uji 10 } \\
Uji t & \\
\hline $\begin{array}{l}\text { Standardized } \\
\text { Coefficients }\end{array}$ & T & Sig \\
\hline $\begin{array}{l}\text { (Constant) } \\
\text { Keselamatan Kerja } \\
(\text { X1 })\end{array}$ & -1.613 & .110 \\
Lingkungan Kerja & -8.593 & .000 \\
$($ X2) & & \\
\hline & 16.055 & .000 \\
\hline
\end{tabular}

1. Pada keselamatan kerja (X1) memiliki signifikan terhadap semangat kerja dgn ditunjukkan dari besarnya nilai $\mathrm{t}$ hitung $=-8.593>\mathrm{t}$ tabel $=1,660$ dengan tingkat signifikan $0,000<0,05$ maka variabel dari keselamatan kerja secara persial berpengaruh terhadap semangat kerja. Maka dengan begitu hipotesis ke-1 yang menyatakan keselamatan kerja berpengaruh terhadap semangat kerja di CV. Mega Jaya Surabaya diterima.

Pada lingkungan kerja (X2)didapat nilai signifikan atas semangat kerja dengan ditunjukkan dari besarnya nilai $\mathrm{t}$ hitung $=16.055>\mathrm{t}$ tabel $=1,660$ dengan tingkat signifikansi 0,000 0,05 maka variabel lingkungan kerja berpengaruh parsial terhadap semangat kerja. Maka begitu hipotesis ke-2 menyatakan lingkungan kerja ada pengaruh terhadap semangat kerja di CV. Mega Jaya Surabaya diterima.

\section{SIMPULAN}

Dari uji yang sudah dilakukan peneliti dengan memakai SPSS versi 24, maka dapat ditarik simpulan:

1. Keselamatan kerja adanya pengaruh dengan cara parsial dgn sig terhadap semangat kerja karyawan. Dengan memakai uji t yang menunjukkan hasil dari $t_{\text {hitung }}$ sebesar $-8,593>1,660$ dan hasil signifikan 0,000<0,05, yang mengandung arti hipotesis diterima dan terbukti kebenarannya.

2. Lingkungan kerja mempunyai pengaruh parsial dan signi terhadap semangat kerja karyawan. Memakai pengujian $t$ yang ditujukan hasil dari $t_{\text {hitung }} 16,055>1,660$ dan hasil signifikan sebesar 0,000<0,05 yang artinya hipotesis diterima dan terbukti benar.

3. Keselamatan kerja, lingkungan kerja memiliki pengaruh simultan pada semangat kerja. Dengan memakai uji f yang menunjukkan hasil dari $f_{\text {hitung }} 239,748>3,09$ dan hasil signifikan sebesar $0,000<0,05$ yang bearti hipotesis diterima dan terbukti kebenarannya.

\section{IMPLIKASI}


Seperti yang diketahui dalam persaingan di era global ini, membuat semangat kerja karyawan yang dibutuhkan perusahaan menjadi semakin meningkat sehingga membuat potensi karyawan dapat dipengaruhi oleh beberapa hal berikut yang merupakan harapan dari peneliti terhadap perusahaan yaitu :

1. Dengan adanya keselamatan kerja, maka akan mencegah terjadinya kecelekaan di tempat kerja. Perusahaan perlu menyediakan alat-alat safety pekerja atau dengan standar keselamatan kerja karyawan agar para pegawai dapat merasa aman dalam bekerja dan para karyawan dapat bekerja secara maksimal. Sehingga dapat ditimbulnya kegembiraan bagi pekerja dengan semangat kerja lebih tinggi.

2. Bagi perusahaan lingkungan kerja sangatlah penting. Karena dapat berpengaruh terhadap pekerja dalam melaksanakan tugasnya. Ruangan kerja perlu untuk dibersikan setiap harinya agar bersih dan terasa nyaman tiap harinya dan akan terjamin tempat kerja bersih, sehat, nyaman, dan aman. Lingkungan kerja yang baik dan nyaman, Maka akan menimbulkan semangat kerja dan membuat para pekerja dapat melaksanakan tugasnya secara optimal.

3. Bagi perusahaan CV. Mega Jaya untuk meningkatkan semangat kerja bagi karyawan maka perusahaan CV. Mega Jaya Surabaya diharapkan dapat mempertahankan adanya keselamatan kerja dan Lingkungan kerja yang lebih baik lagi sesuai yang diharapkan lebih baik lagi. Seperti peralatan kerja yang memadai atau lingungan yang bersih dan terjaga agar mereka dapat bekerja lebih optimal dalam menyelesaikan tugasnya dan mencapai tujuan yang diinginkan.

\section{KETERBATASAN PENELITIAN}

1. Kendala aktivitas di perusahaan yang di teliti.

2. Untuk responden yang mengisi kuesioner penelitian membutuhkan waktu yang lebih lama karena tingkat pendidikan yang berbeda.

\section{DAFTAR RUJUKAN}

Hasibuan, Malayu S.P.2009.ManajemenDasar, Pengertian, Dan Masalah.Jakarta: PT Bumi Aksara.

Manullang, 2006, Dasar-Dasar Manajemen, edisi revisi, cetakan ketujuh, Penerbit : Ghalia Indonesia, Jakarta. 
Nitisemito, Alex S, 2018, Manajemen Personalia (manajemene sumber daya manusia), cetakan ke 6. Jakarta. Ghalia Indonesia.

Sedarmayanti, 2018, Perencanaan dan Pengembangan Sumber Daya Manusia, PT. Refika Aditama, Bandung. 